\title{
Feed Digestion, Growth and Disease Prevalence in Nile Tilapia (Oreochromis niloticus) Cultured at Different Water Exchange Rates in a Recirculating Aquaculture System
}

\author{
Kwasi Adu Obirikorang ${ }^{1, *}\left(\mathbb{D}\right.$, Emmanuel Nkwantabisa Opoku ${ }^{1}$, Benjamin Apraku \\ Gyampoh $^{1}$
}

${ }^{1}$ Kwame Nkrumah University of Science and Technology, Faculty of Renewable Natural Resources, Department of Fisheries and Watershed Management, Kumasi, Ghana.

How to cite

Obirikorang, K.A., Opoku, E.N., Gyampoh, B.A. (2022). Feed Digestion, Growth and Disease Prevalence in Nile Tilapia (Oreochromis niloticus) Cultured at Different Water Exchange Rates in a Recirculating Aquaculture System. Aquaculture Studies, 22(3), AQUAST565. http://doi.org/10.4194/AQUAST565

\section{Article History}

Received 10 November 2021

Accepted 06 January 2022

First Online 14 January 2022

\section{Corresponding Author}

Tel.: +23343561881

E-mail: kaobirikorang.canr@knust.edu.gh

\section{Keywords}

Fish welfare

Growth performance

Nile tilapia

Stress

Water quality

\begin{abstract}
The quality of culture water and the rate of water flow within a culture system can affect fish growth and health. In this study, the effects of different water flow rates on digestion efficiency, growth and welfare of juvenile Nile tilapia (Oreochromis niloticus) (Initial weight: $25.75 \pm 0.47 \mathrm{~g}$ ) were investigated. Fish (15 per tank) were randomly stocked into twelve $150 \mathrm{~L}$ thermoplastic tanks of a recirculating aquaculture system and subjected in quadruplicate groups to water flow rates of $50 \mathrm{Lh}^{-1}$ (Low exchange; LE), $100 \mathrm{Lh}^{-1}$ (Medium exchange; ME) and $150 \mathrm{Lh}^{-1}$ (High exchange; HE) for 72 days. Water quality parameters including total ammonia nitrogen, nitrate and alkalinity, dry matter, protein and lipid digestibilities, somatic growth and some welfare indicators including haematology and disease prevelance were monitored. There were no significant differences in growth among the treatments. Higher prevalence of cataract, fin erosion, oral and dermal lesions were observed in the LE and ME treatments indicating compromised welfare. There were no statistical differences among the treatments in terms of nutrient digestibility. This study has shown that culturing Nile tilapia under moderately high water flow rates of at least $100 \%$ tank water replacement per hour in RAS ensures good growth and feed utilization.
\end{abstract}

\section{Introduction}

The suitability of rearing specific fish species in recirculating aquaculture systems (RAS) depends on many different factors, such as the profitability and biological suitability, and the ideal candidates for RAS culture are mainly high-value temperate species (Bregnballe, 2015). However, with conventional earthen ponds, flow-through systems or cage culture now facing limitations for further expansion due to lack of space, reduced water availability and heightened concerns over environmental impact (Badiola, Mendiola \& Bostock, 2012), there has been a progressive increase in the culture of some tropical fish species such as the Nile tilapia (Oreochromis niloticus) in controlled culture systems such as RAS (Martins, Ochola, Ende, Eding \& Verreth, 2009; Luo et al., 2014; Sri-uam, Donnuea, Powtongsook \& Pasavant, 2016; Obirikorang et al., 2019). Additionally, growing public demands and increased environmental regulations for sustainable aquaculture practices is leading to the development of fish culture systems with advanced water treatment and reuse technologies. In this regard, recirculating aquaculture systems are seen as the solutions to the major challenges facing the sustainable expansion of the aquaculture sector including space availability, reduced water availability and effluent discharges (Martins et al., 2010). 
Recirculation aquaculture is a technology that allows for water reuse in fish production at higher densities, providing more stable and controlled environmental conditions for fish culture (Heinen, Hankins \& Adler, 1996; Yogev et al., 2020), better disease management and enhanced biosecurity (Summerfelt, Sharrer, Tsukuda \& Gearheart, 2009). Although high energy requirement increases the operational costs of RAS (Badiola et al., 2018), it continues to gain wide acceptance due to advantages such as controlled production environment and water conservation (Xiao et al., 2019). Typically, RAS also provides the advantage of species-specific optimum water exchange rate adjustments (Heinen et al., 1996; Obirikorang et al., 2019). Deterioration of water quality due to sub-optimal water flow rates, however, is a challenge in RAS that can have detrimental effects on fish growth due to increased pathogen loads and poor water quality (Timmons, Ebeling, Wheaton, Summerfelt \& Vinci, 2002; Gorle, Terjesen, Mota \& Summerfelt 2019). Recirculating aquaculture operations under suboptimal water quality conditions can only sustain low productivities because of water quality problems that can increase fish stressors and intensify the virulence of disease-causing pathogens. As the relative volumes of clean water entering a recirculating system decrease, the removal of waste metabolites is reduced and the quality of culture water within the system is consequently degraded (Heinen, 1996). The alkalinity, $\mathrm{pH}$, ammonia and nitrate levels of water in RAS systems are highly influenced by water flow rates (Turnbull, Bell, Adams, Bron \& Huntingford, 2005) and the accumulation of metabolites to potentially harmful levels in low exchange RAS could represent a substantial barrier to the expanded utilization of RAS technology (Davidson et al., 2011). On the other hand, high water flow rates might generate high water velocities and induce forced sustained swimming exercise beyond optimal speeds, leading to tissue oxygen debt and the diversion of energy reserves away from somatic growth (Davidson, 1997). Optimal water flow rates in RAS are largely affected design factors such as system geometry and the water inlet and outlet mechanisms and dependent on the requirements of cultured species (Masaló, 2008).

In aquaculture, the Nile tilapia is one of the most widely cultured fish species due to its tolerance of a wide range of environmental conditions, with global production increasing exponentially over the years from 1.3 million tonnes ( $T$ ) in 2003 to about 4.2 million $T$ in 2016 (FAO 2018). The RAS represents a possibility of increasing the production of Nile tilapia in the tropics in the face of limitations for further expansion, reduced water availability and increasing environmental concerns as well asextending the culture range of Nile tilapia beyond the tropical and subtropical regions. In the Netherlands, the $600 \mathrm{~T}$ commercial culture of Nile tilapia is exclusively done in indoor, heated RAS and fillets sold on Dutch and French markets (Martins et al.,
2010). The expansion in the productions of Nile tilapia in RAS requires the establishment of optimum water flow rates of circulating water, and the influence on fish growth and welfare, and physicochemical parameters of culture water. There have been a few studies on the effects of water exchange rates in RAS on growth and other parameters of the Nile tilapia with water exchange rates varying between a wide margin of $70 \mathrm{Lh}^{-1}$ and 720 Lh $^{-1}$ (Tsadik \& Bart, 2007; Martin et al., 2009; Obirikorang et al., 2019). These studies have, however, produced contradictory results. Tsadik \& Bart, (2007) tested different water exchange rates between 70 and $280 \mathrm{Lh}^{-1}$ on the Nile tilapia broodstock and recommended $216 \mathrm{Lh}^{-1}$ as the optimum rate improve productivity under hatchery conditions. The growth performance of juvenile Nile tilapia also positively correlated with increasing water flow exchange rates in a study by Obirikorang et al., (2019). Water exchange rates, however, had no significant effect on the growth performance, feed utilization and all other production traits of Nile tilapia groups grown under water exchange regimes of 480 or $720 \mathrm{Lh}^{-1}$ but larger individuals ( $>300 \mathrm{~g}$ ) may experience growth retardation (Martins et al., 2009). The stress responses elicited in fish during exposures to suboptimal water exchange rates are well documented, but it is unclear how much nutrient digestibility is affected in low water exchange systems. This study is an attempt to further understand the effects of water exchange rates on growth the growth and feed utilization of Nile tilapia which is fast becoming a suitable candidate for culture RAS. This study thus aimed to test the hypothesis that varying water flow rate over defined incremental levels will significantly affect Nile tilapia growth with impaired growth associated with low water exchange regimes, despite the unique tolerance of the species to sub-optimal water quality. Specifically, this study assessed the nutrient digestion efficiency, growth and feed utilisation parameter, and disease prevalence in juvenile Nile tilapia (Oreochromis niloticus) grown under varying water exchange rates in a RAS.

\section{Materials and Methods}

\section{Fish and Experimental Conditions}

Three hundred healthy Nile tilapia from the same cohort (Average weight: $2.10 \pm 0.11 \mathrm{~g}$ ) were nursed in nylon mesh hapas mounted in earthen ponds for 30 days up to the juvenile stage. During the nursery phase, fish were fed ad libitum with a commercial starter feed (Raanan tilapia starter feed; $48 \%$ crude protein, $5 \%$ lipid, Raanan Fish Feed West Africa Ltd, Prampram Ghana). Following the nursery phase, fish were moved from the hapas into a laboratory-based RAS consisting twelve (12) $150 \mathrm{~L}$ cylindro-conical culture tanks, an aeration system, biofiltration and mechanical filtration units (Figure 1) and acclimated to their new environment for 2 weeks before the start of the trials (Obirikorang, Acheampong, 
Duodu \& Skov, 2020). All culture tanks were connected in series and drained into $2000 \mathrm{~L}$ donor tank from which biologically- and mechanically-treated water was resupplied to each culture tank in a continuous flow by a submersible pump (Aqua Forte DM-1300, Sibo Fluidra B.V, Doornhoek, Netherlands). Fish were individually weighed at the start of the trial to ensure uniformity in initial masses (Mean initial mass: $25.75 \pm 0.47 \mathrm{~g}$ ) and randomly stocked at a rate of 15 fish per culture tank taking into consideration the estimated daily fish growth rate, the length of the trial, and the predicted final biomass. For this trial, three different water flow rates were established by adjusting independent water inlet control valves fitted beside each culture tank. The set flow rates corresponded to hourly culture tank water replacement rates of $50 \mathrm{Lh}^{-1}$ or $33 \%$ water replacement per hour (Low exchange; LE), $100 \mathrm{Lh}^{-1}$ or $66 \%$ water replacement per hour (Moderate exchange; ME) and $150 \mathrm{Lh}^{-1}$ or $100 \%$ water replacement per hour (High exchange; $\mathrm{HE}$ ). The main outlet pipe that drained each tank was set to the height of maximum water level and none of the set flow rates created excessive water pressure to cause tank overflow. All treatments were quadruplicated in completely randomized experimental tanks. Water flow indicators installed on each tank were checked daily to ensure that correct flow rates were maintained throughout the trial period. The trial lasted for 72 days and fish were kept under normoxic conditions ( $6.5 \mathrm{mg} \mathrm{O}_{2} \mathrm{~L}^{-1}$ ) using an air pump (Aqua Forte V-30, Sibo Fluidra BV, Doornhoek, Netherlands) that aerated each culture tank via airstones. Throughout the trial, fish were kept under an artificially-controlled photoperiod regime of $12 \mathrm{~h}$ light: $12 \mathrm{~h}$ darkness using twelve $7 \mathrm{~W}$ soft-tone light bulbs overhead each tank to mimic tropical outdoor systems where Nile tilapia are typically found. Fish were hand-fed twice daily with a commercial extruded diet (Raanan Tilapia Supreme Growth Feed $(2.5 \mathrm{~mm}$ pellet size, 33\% crude protein, 6.4\% lipid, Raanan Fish Feed West Africa Ltd, Prampram Ghana) to apparent satiation at 9:00 and 17:00 hrs. Data on fish growth were collected every fortnight by bulkweighing all fish in each tank. The growth and feed intake data were used in the calculation of interval FCRs. At the end of the trial, the remaining fish in each tank were weighed for determinations of growth performance, feed utilization parameters and survival rates using the following equations:

$$
\begin{gathered}
\text { Percentage weight gain }(\%)=\frac{\text { Final weight }(\mathrm{g})-\text { Initial weight }(\mathrm{g})}{\text { Initial weight }(\mathrm{g})} \times 100 \\
\text { Specific growth rate }\left(\% \text { day }^{-1}\right)=\frac{(\text { In Final weight }(\mathrm{g})-\text { In Initial weight }(\mathrm{g}))}{\text { Experimental days }} \times 100 \\
\text { Feed conversion ratio }(\mathrm{FCR})=\frac{\text { Feed fed }(\mathrm{g})}{\text { Weight gain }(\mathrm{g})}
\end{gathered}
$$$$
\text { Survival rate }(\%)=\frac{\text { Number of fish at the end of the experiment }}{\text { Number of fish at the beginning of the experiment }} \times 100
$$

\section{Water Quality Monitoring}

Water was directly sampled from within the water column of each culture tank into $500 \mathrm{ml}$ plastic bottles for the determinations of nutrient accumulation and alkalinity every two weeks following the

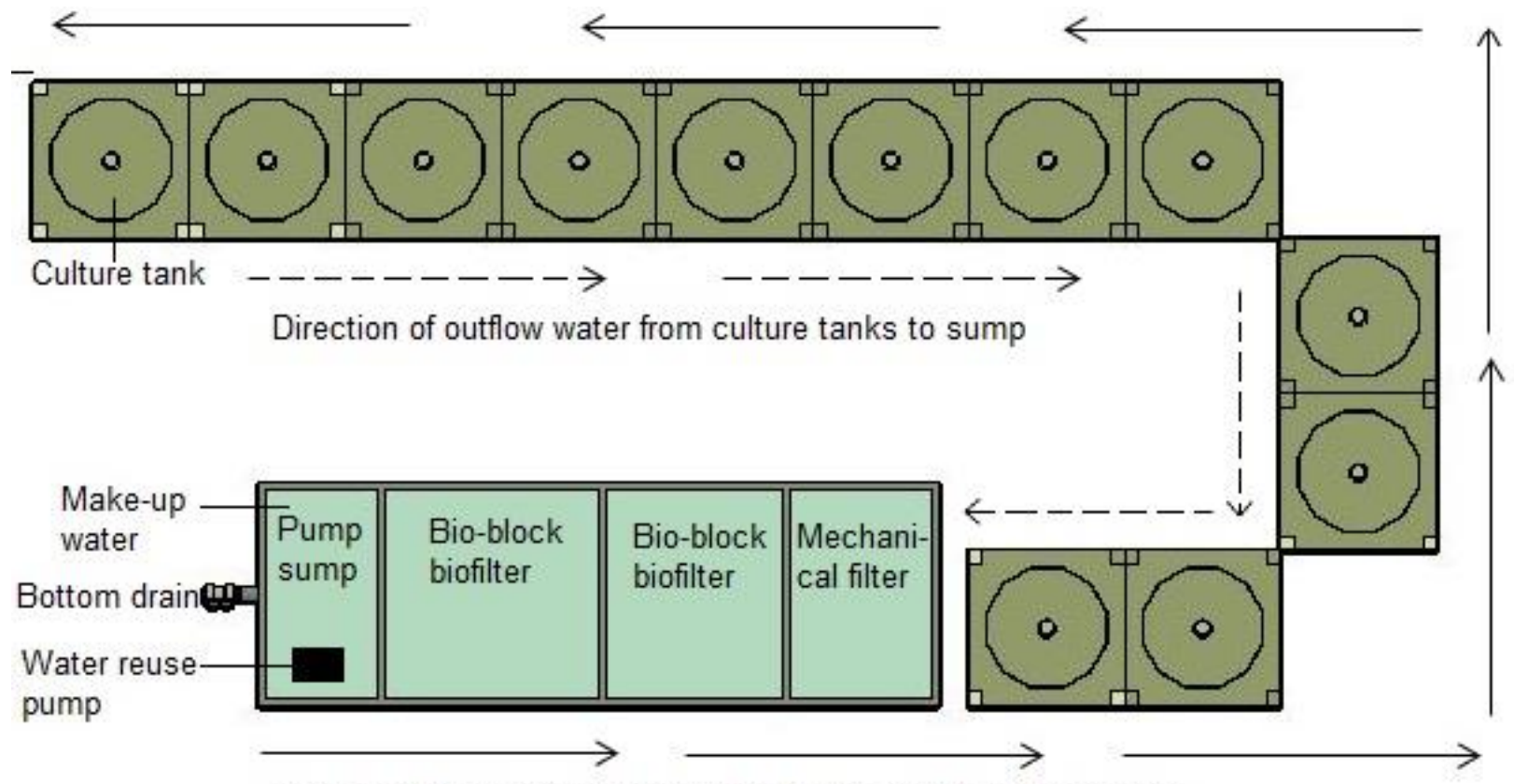

Direction of aerated water from the pump sump to culture tanks

Figure 1. The schematic process flow diagram of the recirculation system shows the main inflow water path from the pump sump to the experimental, cylindro-conical tanks is indicated with full arrows and the main outflow water path from experimental tanks to the mechanical filtration compartment is indicated with broken arrows. Experimental tanks $(12 \times 130 \mathrm{~L})$ and donor tank (Combined volume of $2000 \mathrm{~L}$ ). Denitrification biofilter bio-blocks $\left(2 \times 0.5 \mathrm{~m}^{2} / \mathrm{m}^{3}\right.$ surface area). All lost water via draining of settled solids is replaced manually via pump sump compartment. 
commencement of the trial. The nutrient parameters assessed were total ammonia nitrogen and nitrate and were determined using optical absorbance techniques where specific reagents were added to water samples and the intensity of colour development over specified times measured via photometric method at different wavelengths (YSI 9500 photometer, YSI Inc., Yellow Springs, $\mathrm{OH}$, USA). Ammonia nitrogen was determined using the salicylate procedure where ammonia in the water samples reacted with alkaline salicylate in the presence of chlorine to form a green-blue indophenol complex (Li and Boyd 2016). The Palintest ${ }^{\circledR}$ methods were used to determine nitrate and alkalinity following the manufacturer's specifications. All sample determinations were performed twice. Dissolved oxygen (DO) and $\mathrm{pH}$ were determined in-situ for each culture tank using a multi-parameter probe ( $\mathrm{HI}$ 9828, Hanna Instruments Ltd., Bedfordshire, UK).

\section{Diet Digestibility}

Diet digestibility assessments as influenced by the set water flow rates was performed between the $6^{\text {th }}$ and $8^{\text {th }}$ week of the trial by collecting faecal matter settled beneath each tank over nine (9) days. Fish were fed their respective daily ration and all faeces were collected in settling columns beneath each experimental tank as described previously by Obirikorang, Amisah, Fialor and Skov (2015). To reduce the rates of microbial degradations of the collected faecal matter, each settling column was completely immersed in ice slurry contained in styrofoam boxes. The melted ice in each box replaced every $6 \mathrm{~h}$. Settled faeces were collected twice daily before each feeding event and frozen at -20 ${ }^{\circ} \mathrm{C}$ until analysed. The collected faecal matter samples from each tank were pooled in separate 3-day periods as described previously (Dalsgaard and Pedersen, 2011; Obirikorang et al. 2015). The apparent digestibility coefficients (ADCs) of dry matter, protein and lipid were calculated after the proximate analyses of feed and faecal matter using the direct method described by the equation below;

$$
A D C_{i}=\frac{\left(C_{i}-F_{i}\right)}{C_{i}} \quad \text { (Jobling, 1994) }
$$

Where $\mathrm{i}=$ the macronutrients, $\mathrm{C}=$ consumed amount of $i$, and $F=$ faecal loss of $i$.

\section{Proximate Analysis of Faeces}

The sample bottles containing the collected faecal matter were placed in water and allowed to defrost after which the samples were homogenized using a handheld blender. The dry matter, ash, protein and lipid contents of the faecal matter samples were determined following the standard protocols of the Association of Official Analytical Chemists (AOAC, 2005). Dry matter contents of faeces were determined by oven-drying samples (Gallenkamp hotbox oven CHF097 XX2.5, Gemini B.V., Apeldoorn, The Netherlands) at $105^{\circ} \mathrm{C}$ for $24 \mathrm{~h}$ to ensure the removal of all water. Dry matter was calculated using the equation;

$$
\text { Dry matter }(\%)=\frac{\text { Initial weight }(\mathrm{g})-\text { Final weight }(\mathrm{g})}{\text { Initial weight }(\mathrm{g})} \times 100
$$

The ash content of the faeces was determined by incinerating dry, pre-weighed samples in a muffle furnace (K1252, Heraeus Instruments $\mathrm{GmbH}$, Hanau, Germany) at $550^{\circ} \mathrm{C}$ for $4 \mathrm{~h}$. Ash was calculated using the equation;

$$
\text { Ash }(\%)=\frac{\text { Dry weight of ash }(\mathrm{g})}{\text { Dry weight of faecal sample }(\mathrm{g})} \times 100
$$

The nitrogen contents of faecal samples were determined using an automatic Kjeldahl setup (Foss Kjeltec 2200, Foss, Hilleroed, Denmark) equipped with digestion, distillation and titrator units. Protein was calculated from the determined nitrogen contents using the equation;

$$
\text { Crude Protein }(\%)=\text { Nitrogen }(\%) \times 6.25
$$

The level of crude lipid in faecal samples was determined by the method of Bligh \& Dyer (1959) by extracting the residual lipid in $2 \mathrm{~g}$ samples with petroleum ether in a Soxhlet extractor. The crude lipid contents of the samples were determined using the equation;

$$
\text { Crude lipid (\%) }=\frac{\text { Weight of extracted lipid }(\mathrm{g})}{\text { Weight of faecal sample }(\mathrm{g})} \times 100
$$

\section{Fish Welfare and Disease Monitoring}

Fish were continuously monitored daily for macroscopic manifestations of external signs of stress and diseases. The observations were limited to gross signs of disease such as cataracts, dermal ulcerations, fin erosion, oral lesions and fin (pelvic, pectoral, dorsal and caudal fins) fraying. The severity of each pathological sign was distinctly evaluated and graded as mild or severe (Obirikorang et al., 2019). Prevalence for each disease condition within the different treatments was calculated as the proportion (percentage) of the total population of individual fish within a treatment showing signs of a disease condition. Disease prevalence was categorized and calculated separately for individuals exhibiting either mild or advanced forms of the condition and displayed as a triangular quaternary plot. Total prevalence for each disease condition within an experimental unit was calculated as the sum of all individual within each experimental unit exhibiting signs of that condition, regardless of the severity and the distribution plotted as boxplots. 


\section{Haematological Analysis}

At the end of the trial, 12 fish under their respective water exchange treatments ( 3 fish per tank) were carefully netted from each tank and anaesthetized in $100 \mathrm{mg} \mathrm{L}^{-1}$ propofol (Fresenius Kabi AB, Uppsala, Sweden) solution. About $2 \mathrm{ml}$ of blood samples were drawn by caudal sampling from each anaesthetized fish into Vacutainer ${ }^{\circledR}$ tubes (Becton Dickinson, Franklin Lakes, NJ, USA) containing EDTA as an anticoagulant. Haemolysed or insufficient sample volumes were discarded. After sampling, fish were placed in tanks of aerated water for recovery. The haematological analysis was carried out immediately after sample collection using the automated blood cell count method (TranDuy, Schrama, van Dam \& Verreth, 2008; Fazio et al. 2012). Validation of the reliability of the automated method against manual haematological analyses using a Neubauer haemocytometer (for RBC count), the cyanmethaemoglobin (for haemoglobin) and microhaematocrit centrifugation (haematocrit) methods by Fazio et al. (2012) indicated no significant differences in the results of the two methods. All samples were analysed in duplicate by the same operator. The haematological analysis was carried out as complete blood counts with a 3-part differential (Red blood cells (RBC), white blood cells (WBC) and platelet indices) determined by an automated haematology analyzer (CELL-DYN 1800, Abbot Laboratories, Irving, TX, USA).

\section{Statistical Analysis}

Data are presented as mean \pm SD in tables. Oneway ANOVA was used to test for differences between the means of measured and calculated parameters among the various fish groups over the trial period. In instances where there were significant differences among the treatment means, they were compared using the Tukey multiple comparison test (Zar 1999). In all instances, differences were considered significant at $\mathrm{P}<0.05$. In instances where measurements were taken on individual fishes from the experimental tanks, data were not treated as subsamples or pseudoreplicates but rather, statistical analyses were carried out on replications considered at tank levels. All data were tested for normality using the Kolmogorov-Smirnov test and percentages arcsine-transformed before analysis (Zar 1999). Statistical analyses were executed using SigmaPlot ver. 12.0 (Systat Software Inc., San Jose, CA, USA).

\section{Results}

\section{Water Quality}

Within $72 \mathrm{~h}$ of commencement of the study, culture water of the low makeup treatment turned qualitatively more turbid relative to the high and medium makeup systems. This obvious visible difference was persistent throughout the study. All water quality indices recorded for the various treatments were within published acceptable ranges for Nile tilapia rearing. Ammonia, nitrate and alkalinity were significantly higher $(P<0.05)$ in the low exchange treatment relative to the high and medium exchange groups (Table 1). The differences in the water inflow rates from the main reservoir tank into the culture tanks resulted in significant differences $(P=0.0043)$ in $D O$ concentrations among the different treatments. The mean DO levels in the HE, ME and LE culture tanks over the trial period were $6.46 \pm 0.17,6.22 \pm 0.20$ and $5.91 \pm 0.27 \mathrm{mgL}^{-1}$, respectively. The different water flow rates also significantly influenced $\mathrm{pH}$ levels $(\mathrm{P}=0.0039)$.

\section{Growth and Feed Utilization}

Although the fish under the high water exchange treatment had improved growth performance and feed utilization parameters, there were no significant differences $(P>0.05)$ in any of the recorded or calculated parameters after the trial (Table 2). The final wet fish weights were $125.69,126.98$ and 135.17 g respectively for the LE, ME and HE treatments. All other growth parameters were similarly affected in the pattern of $\mathrm{HE}$ $>$ ME > LE (Table 2). The interval weight gains calculated over two-week periods were fairly similar although towards the end of the trial the weight gain among the three treatments were in the order of $\mathrm{HE}>\mathrm{ME}>\mathrm{LE}$. (Figure 2) There were, however, no significant differences among treatments for all the fortnight weight gains. Feed intakes (g fish ${ }^{-1}$ ) were slightly affected by the differences in water flow rates and were statistically indistinguishable among the treatments.

Table 1. Physicochemical water quality parameters of culture water in tanks under different water exchange rates $(50,100$ and $\left.150 \mathrm{Lh}^{-1}\right)$

\begin{tabular}{|c|c|c|c|c|}
\hline Parameter & $50 \mathrm{Lh}^{-1}$ & $100 \mathrm{Lh}^{-1}$ & $150 \mathrm{Lh}^{-1}$ & $p$-value \\
\hline Dissolved Oxygen $\left(\mathrm{mgL}^{-1}\right)$ & $5.91 \pm 0.27^{a}$ & $6.22 \pm 0.20^{c}$ & $6.46 \pm 0.17^{c}$ & 0.0043 \\
\hline $\mathrm{pH}$ & $6.30 \pm 0.12^{\mathrm{a}}$ & $6.53 \pm 0.14^{c}$ & $6.75 \pm 0.07^{c}$ & 0.0039 \\
\hline Ammonia $\left(\mathrm{mgL}^{-1}\right)$ & $0.04 \pm 0.01^{\mathrm{a}}$ & $0.03 \pm 0.01^{b}$ & $0.01 \pm 00^{c}$ & 0.0142 \\
\hline Nitrate $\left(\mathrm{mgL}^{-1}\right)$ & $4.13 \pm 0.31^{\mathrm{a}}$ & $3.51 \pm 0.04^{\mathrm{ab}}$ & $3.14 \pm 0.50^{b}$ & 0.0310 \\
\hline Alkalinity $\left(\mathrm{mgL}^{-1}\right)$ & $143.10 \pm 4.86^{a}$ & $111.90 \pm 5.10^{\mathrm{ab}}$ & $98.10 \pm 11.3^{b}$ & 0.0010 \\
\hline
\end{tabular}

The results are presented in mean \pm standard deviation of data from quadruplicate groups $(n=4)$. Within a row, means that do not share a common superscript letter differ significantly $(P<0.05)$. Absence of letters indicates no significant difference between the treatments, according to one way ANOVA, followed by Tukey's Multiple Comparison Test. 
Feed conversion efficiencies were marginally improved in the high water exchange group compared to the medium and low exchange groups. Mean FCRs ranged from 1.43 to 1.51 for the treatments. Interval FCRs calculated fortnightly showed a trend of improved feed utilization after the first two weeks (Figure 3). The interval FCRs from weeks 4 to 10 were generally $<2$. The low exchange environments caused slightly increased mortality, but survival rates among the three treatments were statistically similar $(P=0.6181)$

\section{Disease Prevalence}

Visible signs of cataracts and oral lesions were generally observed in fish from the ME and LE regimes two weeks after initiation of study. Fish cultured under the LE and treatments were more susceptible to cataracts than the HE fish. The mean prevalence of cataract in the ME and LE treatments were $32 \%$ and $40 \%$ respectively, which were significantly higher $(P=0.0005)$ and approximately 3- and 4-fold higher than the prevalence in the HE treatment (Figure 4). Similarly, the prevalence of dermal ulcerations increased significantly $(P=0.0231)$ with increasing residence times of culture water. Dermal ulcerations were the least prevalent histological symptom among the various treatments. The proportions of the populations under the different treatments exhibiting signs of dermal ulcerations ranged from $3 \%$ (HE fish) to $12 \%$ (LE fish). These dermal ulcerations were usually characterized by skin ulcers which in severe cases developed superficial cotton-like growth suspected to be saprolegniasis. This fungal growth was mainly a secondary infection that developed after damage to the fish integument. Only $4 \%$ of the fish under the HE treatment developed epidermal lesions compared to $37 \%$ of the LE fish. These lesions first developed as small, focal infections that rapidly spread over the surface of the body. The prevalence of lesions around the oral cavity was fairly similar among the treatments $(P=0.1796)$ and ranged from $17 \%$ (HE fish) to $28 \%$ (LE fish). Reducing water flow rates increased the prevalence of fin erosions. Advanced forms of all the assessed diseased conditions as shown in Figure 5 (a, b, c), were generally associated with the LE and ME fish compared to the HE fish (Figure 6). Although there were incidents of all the assessed disease conditions in the $\mathrm{HE}$ treatment, all the observed infections were mild and none progressed into advanced forms. Although not

Table 2. Growth performance and feed utilization of Oreochromis niloticus exposed to varying water flow rates of 50, 100 and $150 \mathrm{~L} \mathrm{~h}^{-1}$ in a 72 day trial

\begin{tabular}{|c|c|c|c|c|}
\hline Parameter & $50 \mathrm{Lh}^{-1}$ & $100 \mathrm{Lh}^{-1}$ & $150 \mathrm{Lh}^{-1}$ & $p$-value \\
\hline Mean initial body weight (g) & $26.10 \pm 0.44$ & $24.96 \pm 1.18$ & $26.20 \pm 2.27$ & 0.5606 \\
\hline Mean final body weight (g) & $125.69 \pm 3.09$ & $126.98 \pm 13.62$ & $135.17 \pm 5.37$ & 0.3978 \\
\hline Weight gain (\%) & $381.82 \pm 15.46$ & $408.07 \pm 38.55$ & $418.09 \pm 42.54$ & 0.4576 \\
\hline Feed Intake (g fish ${ }^{-1}$ ) & $138.95 \pm 4.99$ & $150.43 \pm 15.75$ & $149.12 \pm 3.62$ & 0.3909 \\
\hline Specific growth rate $\left(\%\right.$ day $\left.^{-1}\right)$ & $2.15 \pm 0.10$ & $2.26 \pm 0.10$ & $2.28 \pm 0.12$ & 0.3105 \\
\hline Feed conversion ratio & $1.51 \pm 0.16$ & $1.60 \pm 0.04$ & $1.43 \pm 0.10$ & 0.2028 \\
\hline Survival rate (\%) & $80.00 \pm 11.55$ & $75.56 \pm 3.85$ & $84.44 \pm 13.88$ & 0.6181 \\
\hline
\end{tabular}

The results are presented in mean \pm standard deviation of data from quadruplicate groups $(n=4)$. Within a row, means that do not share a common superscript letter differ significantly $(P<0.05)$. Absence of letters indicates no significant difference between the treatments, according to one way ANOVA, followed by Tukey's multiple comparison test.

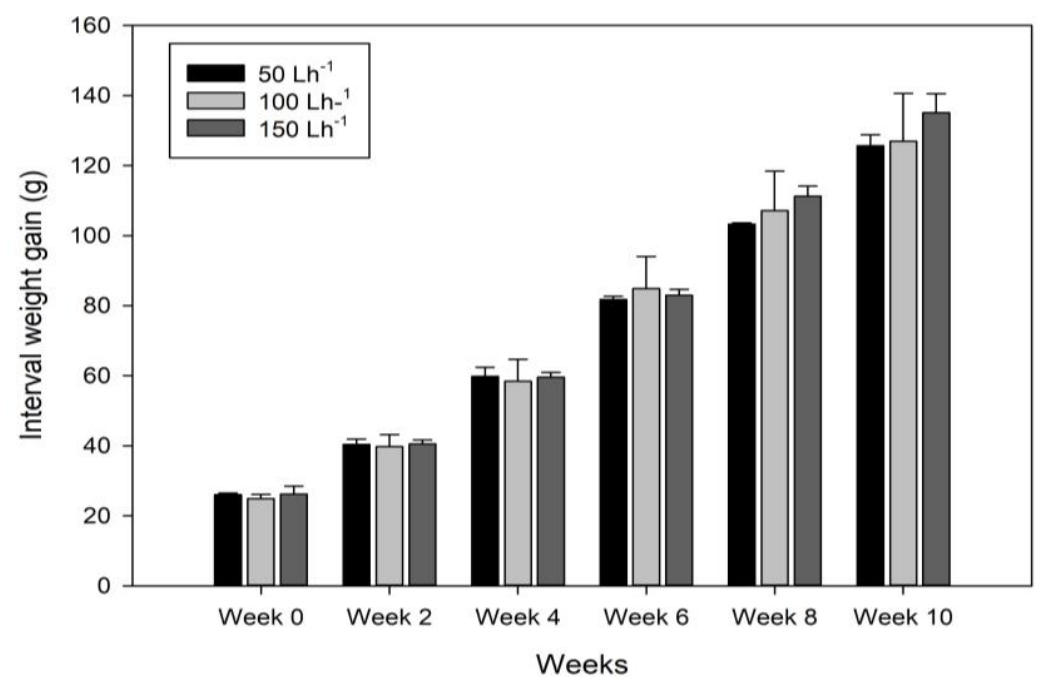

Figure 2. Prevalence of disease conditions in Nile tilapia cultured under different water flow regimes $\left(50,100\right.$ and $\left.150 \mathrm{~L} \mathrm{~h}^{-1}\right)$ for 10 weeks $(n=4)$. For each disease condition, treatments that do not share a common lower case letter differ significantly $(P<0.05)$. Data are presented as the minimum and maximum prevalence for each disease condition within each treatment (Median lines are represented as black lines inside each bar). 
quantitatively assessed, reduced feeding, sluggishness in swimming, isolation at the bottom of the tank and huddling at the tank surface were some of the observed behavioural signs of the infections.

\section{Nutrient Digestibility}

Apparent nutrient digestibility coefficients for dry matter, lipid, protein, ash and nitrogen-free extracts are as shown in Table 3. There was a trend of decreasing dry matter ADCs with decreasing water exchange rates although there were no statistical differences among the treatments. Dry matter ADC were 57.03 \pm 3.67 , $59.10 \pm 6.78$ and $64.26 \pm 2.56 \%$, respectively for the $L E$, ME and HE groups. Crude protein, crude lipid and ash $A D C s$ were similarly affected by the different water exchange regimes with slightly improved ADCs recorded for the HE fish. There were, however, no significant differences in any of the nutritional parameters among the treatments.

\section{Haematological Analysis}

Haematological parameters analyzed for the fish under the different water exchange groups are as reported in Table 4. Fish kept under low water flow rates had relatively elevated RBCs and other quantitative RBC parameters like haematocrit and haemoglobin. Similarly, other red cell indices like mean corpuscular volume (MCV), mean corpuscular haemoglobin (MCH), and mean corpuscular haemoglobin concentration (MCHC) were consistently higher in the low exchange

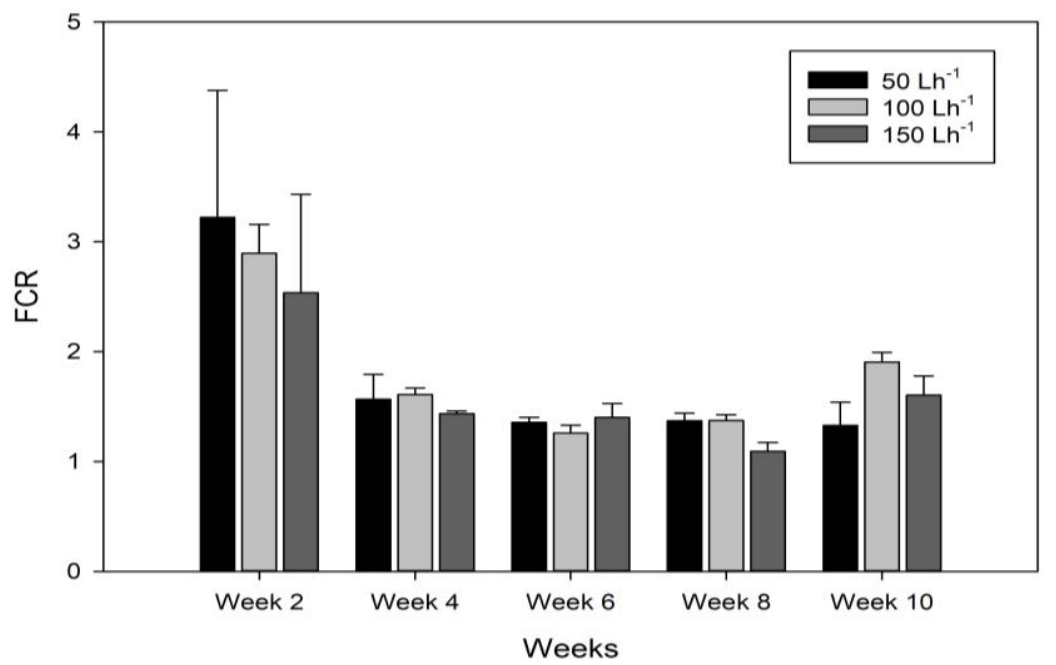

Figure 3. A two-dimensional quaternary plot showing the relative proportions and distribution of healthy, mildly and severely affected fish with cataracts, dermal ulcerations, epidermal and oral lesions or fin erosions after 10 weeks of culture under different water flow rates of 50,100 and $150 \mathrm{~L} \mathrm{~h}^{-1}(\mathrm{n}=4)$

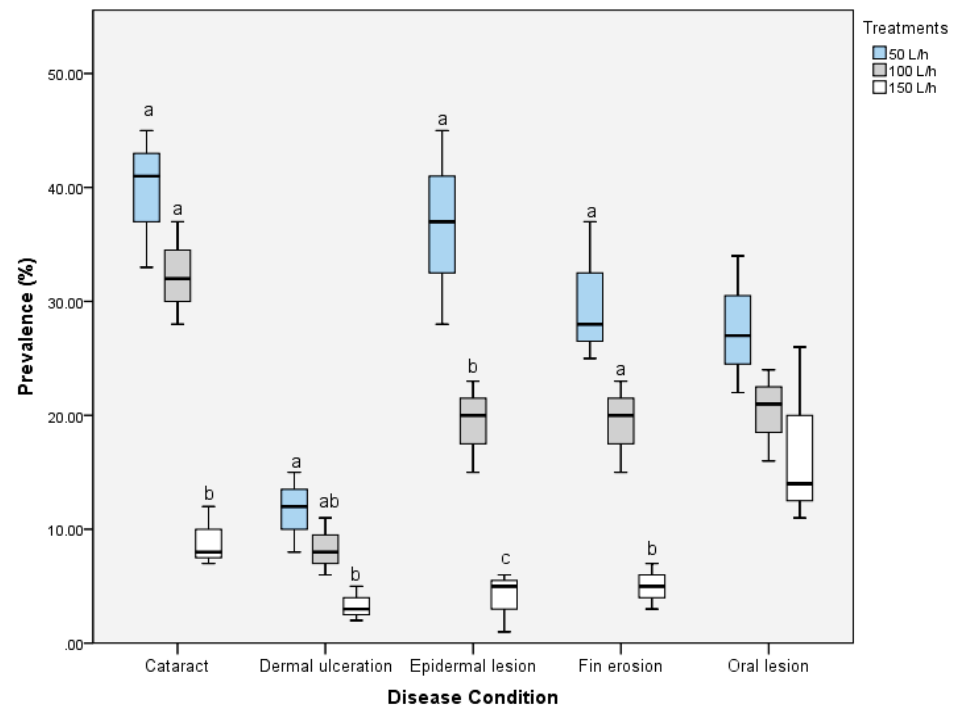

Figure 4. Prevalence of disease conditions in Nile tilapia cultured under different water flow regimes $\left(50,100\right.$ and $\left.150 \mathrm{~L} \mathrm{~h}^{-1}\right)$ for 10 weeks $(n=4)$. For each disease condition, treatments that do not share a common lower case letter differ significantly $(P<0.05)$. Data are presented as the minimum and maximum prevalence for each disease condition within each treatment (Median lines are represented as black lines inside each bar). 

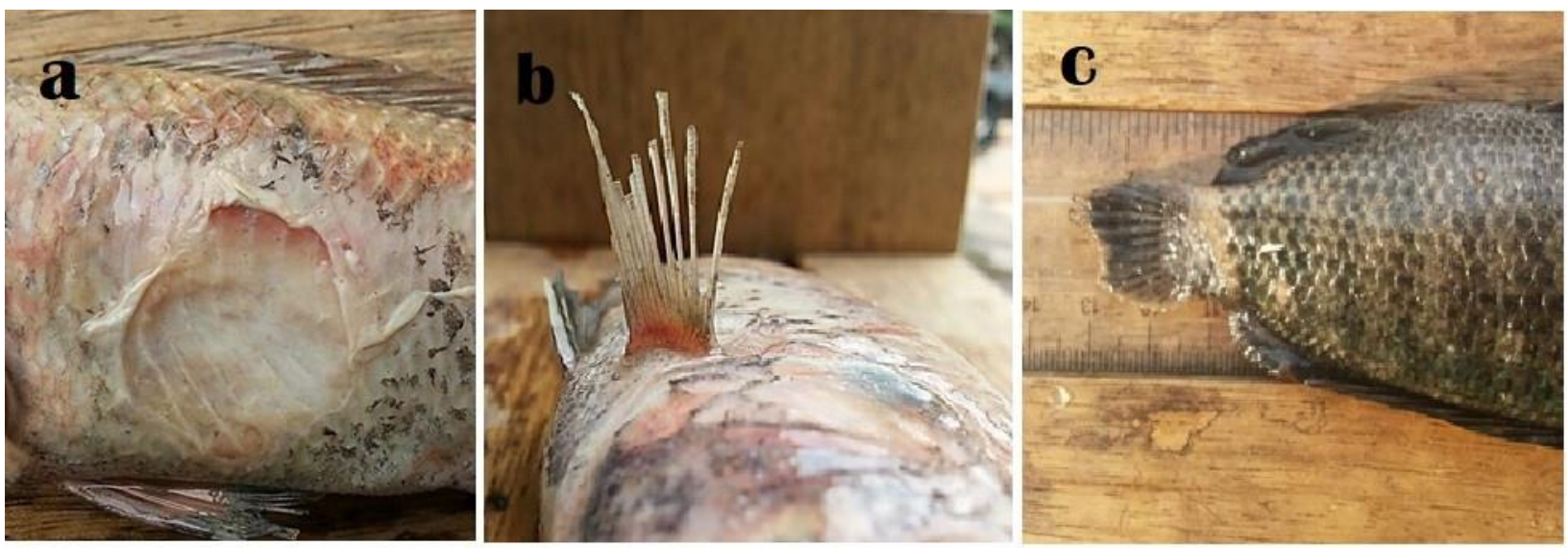

Figure 5. Conditions of dermal ulceration (a), frayed pectoral fin (b) and eroded caudal fin categorized as "advanced" during the study.

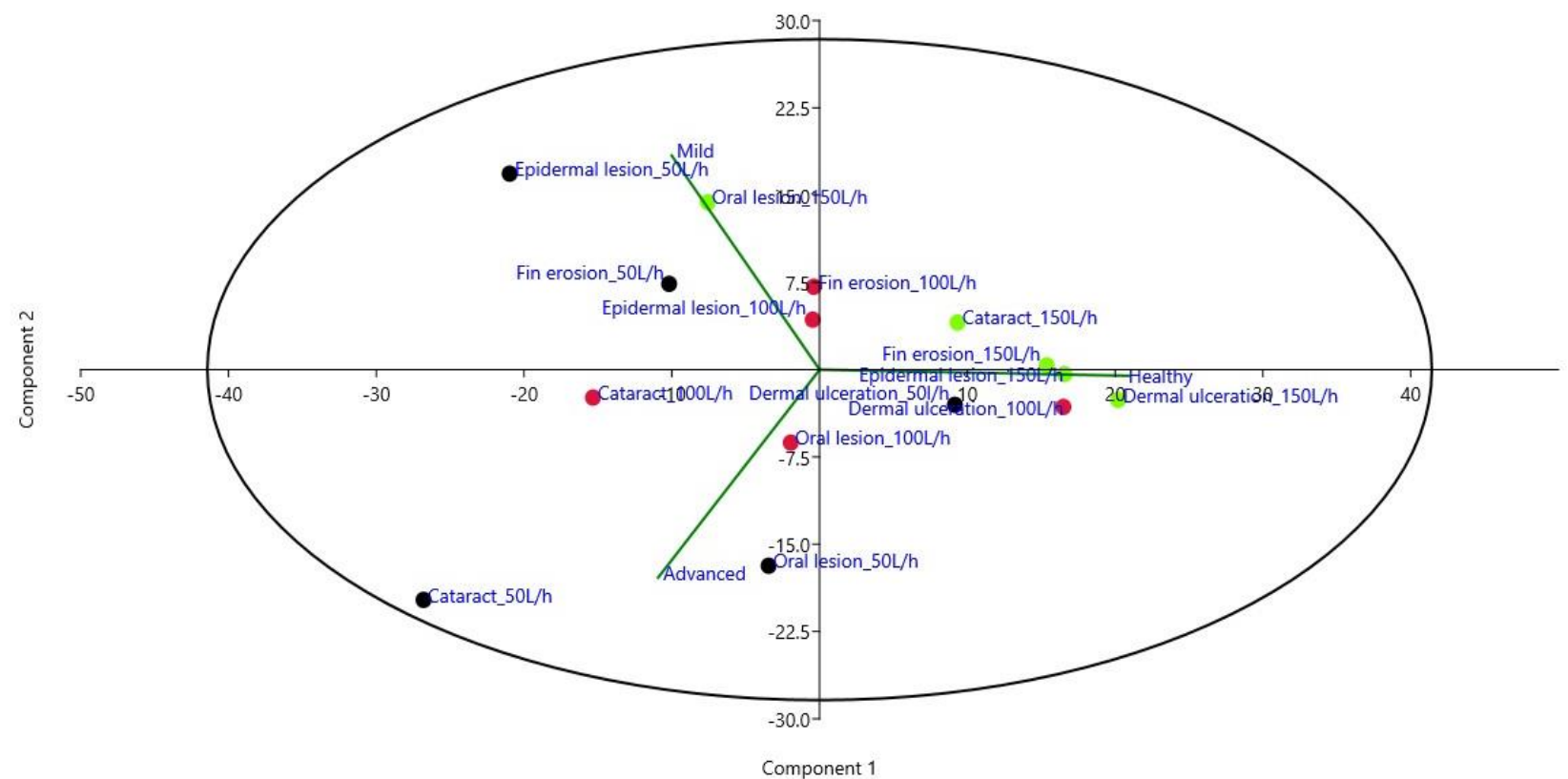

Figure 6. A PCA biplot showing the relationship between water flow rates and prevalence of healthy, mildly and severely affected fish with cataracts, dermal ulcerations, epidermal and oral lesions or fin erosions after 10 weeks of culture.

fish, compared to the medium and high exchange fish. There were, however, no significant differences $(P>0.05)$ in any of these RBC parameters among the treatment groups. There were also elevated levels of the blood cells associated with immune response (White blood cells) and injuries (platelets) in the LE fish compared to the ME and HE fish.

\section{Discussion}

This study assessed the effects of water flow rates on the growth performance, feed digestibility, welfare of Nile tilapia as well as on the quality of culture water. Except for water quality parameters, there was no significant difference in any measured parameters. There were significant differences in all the recorded water quality parameters for the different water exchange regimes. The detected differences were caused by variations in water flow rates since the quality of the inflowing water was the same for all treatments. As the relative volumes of clean water entering a culture tank decrease, the amount of waste metabolites eliminated per unit time is reduced and quality of culture water within the system is consequently degraded (Summerfelt et al., 2009). A study by Good et al. (2009) revealed that within $24 \mathrm{~h}$ of trial initiation, culture water was observed to be qualitatively darker and more turbid in the low makeup treatment relative to the high makeup systems, and these obvious visible differences were persistent throughout the study period. This could be due to reduced elimination rates of solid wastes, primarily faecal matter and uneaten feed within the system. Metabolites and solid wastes accumulating within low water exchange systems as a result of the significant lags in waste removal rates could serve as substrates for microbes and decrease dissolved 
oxygen levels as a result of microbial respiration (Good et al., 2009). This could explain the significant differences in dissolved oxygen levels in the various treatments despite keeping aeration rates constant in all the culture tanks in this study. The significantly lower $\mathrm{pH}$ in the low makeup tanks could be as a result of a higher accumulation of $\mathrm{CO}_{2}$ excreted from fish and bacterial metabolism because of the long residence time of wastewater. The reaction of dissolved $\mathrm{CO}_{2}$ with the culture water results in the release of $\mathrm{H}+$ ions that can significantly lower pH (Skov, 2019). The significantly higher ammonia, nitrate and alkalinity levels in the LE treatment relative to the ME and HE treatments are similar to results reported by Obirikorang et al., (2019), Schram et al., (2009) and Good et al., (2009), who suggested that this could be due to the low rates of waste removal, principally ammonia which is oxidized to nitrate.

Increasing water flow rates resulted in improvements in growth performance and feed utilisation indices, although there were no significant differences among the treatments. The higher growth parameters of the high makeup group are consistent with the findings obtained for rainbow trout, Oncorhynchus mykiss (Good et al., 2009) and Nile tilapia (Obirikorang et al., 2019) grown under different water exchange regimes. The lower growth performance and feed efficiency responses in the fish exposed low water flow rates could be linked to the significant reductions in dissolved oxygen levels in that treatment. This agrees with previous data obtained in the study by Tran-Duy et al. (2008) that observed lower growth of Nile tilapia cultured under dissolved oxygen levels lower than the optimum. The reduced growth under long-term, chronically lower dissolved oxygen can be explained as the stressful condition increasing the energetic cost of ventilation which can potentially decrease the amount of energy available for growth (Kramer, 1987; Perry et al., 2009). The metabolic cost of ventilation, expressed as a proportion of metabolic energy in Nile tilapia under normoxic condition is about 3\%, but increases to $20 \%$ during hypoxia exposure (Fernandes \& Rantin, 1994). The constant exposure of the hypoxia group to nearcritical $\mathrm{O}_{2}$ level for the duration of the trial could imply the allocation of some portions of available metabolic energy towards ventilatory pump activity to maintain $\mathrm{O}_{2}$ uptake, which resulted in the slight growth reduction. The fish cultured under the LE regime also had decreased feed intake compared to the $\mathrm{ME}$ and $\mathrm{HE}$ regimes. Reducing feed intake under stressful conditions is a proxy to saving energy that otherwise would have been used in the digestion process in fish, which can reduce fish growth (Magnoni et al., 2018). Additionally, the stress imposed by the poor water quality in the LE treatment could have also slightly retarded growth. Better survival rate (\%) of the HE group signifies low susceptibility to prevailing diseases, injuries and stressors. According to Summerfelt (2004), virulent pathogens are efficiently removed and less prevalent in high water replacement recirculating tanks. Consequently, fish kept in waters of high exchange rates were the least susceptible to the relatively low pathogen populations present, which could also have resulted in the improved growth performance of the HE fish. Even though there were no significant effects of the different water exchange treatments on nutrient digestibility,

Table 3. Apparent digestibility coefficients (ADCs) of macronutrients in O. niloticus groups exposed to varying water flow rates

\begin{tabular}{lcccc}
\hline Dietary component & $50 \mathrm{Lh}^{-1}$ & $100 \mathrm{Lh}^{-1}$ & $150 \mathrm{Lh}^{-1}$ & $p$-value \\
\hline Dry matter (\%) & $57.03 \pm 3.67$ & $59.10 \pm 6.78$ & $64.26 \pm 2.56$ & 0.1349 \\
Crude protein (\%) & $85.69 \pm 1.10$ & $86.20 \pm 4.10$ & $88.5 \pm 2.57$ & 0.3758 \\
Crude lipid (\%) & $80.66 \pm 2.96$ & $82.14 \pm 3.83$ & $85.71 \pm 5.38$ & 0.2656 \\
Ash (\%) & $79.84 \pm 1.70$ & $81.13 \pm 6.15$ & $81.67 \pm 2.98$ & 0.8118 \\
\hline
\end{tabular}

The results are presented as mean \pm standard deviation of data from quadruplicate groups $(n=4)$. Within a row, means that do not share a common superscript letter differ significantly $(P<0.05)$. Absence of letters indicates no significant difference between the treatments, according to one way ANOVA, followed by Tukey's Multiple Comparison Test.

Table 4. Haematological parameters of $O$. niloticus exposed to varying water flow rates of 50, 100 and 150 Lh $^{-1}$ for 72 days.

\begin{tabular}{|c|c|c|c|c|}
\hline Analyte & $50 \mathrm{Lh}^{-1}$ & $100 \mathrm{Lh}^{-1}$ & $150 \mathrm{Lh}^{-1}$ & $p$-value \\
\hline Red Blood Cells $\left(\times 10^{6} / \mu \mathrm{L}^{-1}\right)$ & $1.87 \pm 0.29$ & $1.73 \pm 0.03$ & $1.59 \pm 0.18$ & 0.0960 \\
\hline Haemoglobin (g/dL) & $10.63 \pm 0.56$ & $10.3 \pm 0.7$ & $10.08 \pm 1.19$ & 0.9095 \\
\hline Haematocrit (\%) & $30.88 \pm 5.95$ & $27.57 \pm 1.61$ & $25.42 \pm 1.31$ & 0.1856 \\
\hline $\mathrm{MCV}(\mathrm{fl})$ & $163.56 \pm 8.47$ & $162.83 \pm 10.01$ & $160.52 \pm 8.61$ & 0.7770 \\
\hline $\mathrm{MCH}(p g)$ & $62.48 \pm 6.87$ & $60.23 \pm 4.54$ & $59.88 \pm 8.19$ & 0.0663 \\
\hline $\mathrm{MCHC}(\mathrm{g} / \mathrm{dL})$ & $39.08 \pm 6.05$ & $33.67 \pm 1.12$ & $30.2 \pm 6.04$ & 0.0616 \\
\hline White Blood Cells $\left(\times 10^{5} / \mu \mathrm{L}^{-1}\right)$ & $2.82 \pm 0.09$ & $2.79 \pm 0.14$ & $2.74 \pm 0.18$ & 0.9470 \\
\hline Platelets $\left(\times 10^{5} / \mu \mathrm{L}^{-1}\right)$ & $1.91 \pm 0.33$ & $1.46 \pm 0.45$ & $1.38 \pm 0.68$ & 0.4139 \\
\hline
\end{tabular}

The results are presented in mean \pm standard deviation of data from quadruplicate groups $(n=4)$. Within a row, means that do not share a common superscript letter differ significantly $(\mathrm{P}<0.05)$. Absence of letters indicates no significant difference between the treatments, according to one way ANOVA, followed by Tukey's Multiple Comparison Test. MCV = Mean Corpuscular Volume, MCH = Mean Corpuscular Haemoglobin, MCHC = Mean Corpuscular Haemoglobin Concentration 
lower nutrient ADCs were associated with the LE treatment. Oxygen plays a central role in the derivation of energy from aerobic metabolic processes, and shortfalls in the supply of dissolved oxygen may reduce the utilisation of dietary energy for metabolic processes and growth in the long term (Glencross, 2009).

The incidence of disease conditions in the different water exchange treatments appeared to be linked to the respective water quality conditions. Signs of advanced fin and epidermis erosion, dermal ulcerations, cataracts and oral lesions were more prevalent in the low water exchange group. Chronic exposure to poor culture water conditions may lead to immunosuppression in fish and increase susceptibility to different diseases. Similar to the results of this study culturing turbot (Scophthalmus maximus) in low water exchange RAS induced maladaptive or negative consequences which manifested as increased incidence of disease conditions in addition to reduced growth (Schram et al., 2009). Good et al., (2009) reported a higher incidence of epidermal inflammations in $O$. mykiss cultured in systems with low water flow rates. Besides the energetic costs associated with the poor physicochemical water quality stressors, high pathogen load as a result of the slow water renewal rates in the LE treatment can also be implicated in the high prevalence of disease conditions. It was suggested that the high pathogen load in the low makeup system could be the cause of the infection. Counts of pathogenic agents such as heterotrophic bacteria in low water exchange systems can be 5 times higher than that in high water exchange systems (Davidson, Good, Welsh, Brazil \& Summerfelt, 2008). The prevalence of cataracts, dermal ulcerations, oral lesions and fin erosions in fish under the low exchange regimes could thus be due to the synergistic effect of sub-optimal culture conditions including poor water quality, stressors and increased populations of opportunistic pathogens. Although not quantitatively measured in this study, the reductions in water flow rates possibly led to the build-up of $\mathrm{CO}_{2}$ in the culture tanks of the LE treatment which could have increased the prevalence of cataracts in that treatment. Some studies have identified correlations between $\mathrm{CO}_{2}$ levels and cataract formation been documented in the Atlantic cod, Gadus morhua (Moran, Tubbs \& Støttrup, 2012; Neves \& Brown, 2015). Exposure of the Atlantic cod juveniles to elevated $\mathrm{CO}_{2}$ levels significantly increased the incidence of cataracts. The possible mechanisms by which dissolved $\mathrm{CO}_{2}$ can induce cataract formation include limited oxygen delivery rates to the eye, $\mathrm{CO}_{2}$ induced disruption of the $\mathrm{pH}$ levels and ionic balance in the eye (Moran, Tubbs \& Støttrup, 2012).

The haematological analyses of the fish under the LE culture conditions appeared to reveal disrupted homeostasis in some of the measured parameters, including the RBC indices. Variations in haematological profiles of fish, especially the red blood cell component can be interpreted as compensatory adaptive responses to improve the oxygen-carrying capacity and maintain efficient gaseous exchange (Hanan, 2013). The relationship between DO levels and red blood cells, haemoglobin and haematocrit index values in this study confirms this. Long-term exposure to the reduced DO levels induced by the low water flow rates of the LE treatment resulted in the group demonstrating some level of oxyregulating adaptation by increasing red blood cell, haemoglobin and haematocrit levels. The release of red blood cells via spleeny contraction is also a common response in fish exposed to hypoxia (Jobling, 1994). Although the red blood cells of fish are sensitive to various environmental stress, the basic quantitative RBC parameter like haemoglobin concentration tend to remain stable due to considerable compensatory potential during long term exposure to stressful conditions (Vosylienè, 1999). According to Weber \& Jensen (1988), although erythropoiesis and haemoglobin synthesis are induced in response to some water quality stressors, they usually require longer periods and may only be involved in long-term adaptation. This probably explains why the levels of circulating haemoglobin were not statistically distinguishable among the fish under the different water exchange treatments of the present study. The slightly elevated platelet and WBC counts of the LE and ME fish relative to the $\mathrm{HE}$ fish were likely in response to the high incidence of open lesions and pathogenic infections in the low water exchange fish. White blood cells, which are the regulators of fish immune system increase as fish are exposed to chronic poor water quality (Hanan, 2013). In this study, the relatively higher levels of WBC counts in the LE and ME exchange groups could be due to generalized immune response and immunityboosting against virulent pathogens.

\section{Conclusion}

This study has revealed with enough evidence that varying water flow rates significantly influence some physicochemical parameters of culture water, although the strong innate and adaptive immune response of Nile tilapia renders enough resistance against significant alterations in somatic growth and haematological status. It is, however, possible that under prolonged culture periods beyond the trial duration, fish growth might be significantly impaired in the low water flow rate treatment. Chronic exposures of the species to poor water quality under low water exchange conditions, however, predisposes it to significantly higher prevalence of disease conditions despite its hardy nature. Culturing Nile tilapia under moderately high water flow rates of $100 \%$ water exchange per hour can safeguard Nile tilapia welfare in RAS setups.

\section{Ethical Statement}

All the experimental protocols and procedures involving fish were performed in accordance with the standard operating procedures of the Kwame Nkrumah 
University of Science and Technology's Animal Research Ethics Committee (AREC) (Policy number 0016).

\section{Funding Information}

The Government of Ghana University Lecturers' Research Allowance

\section{Author Contribution}

Conception or design of the work: KAO, EON, BAG Data collection: EON, KAO

Data analysis and interpretation: BAG, KAO

Drafting the article: KAO

Critical revision of the article, EON, BAG

Final approval of the version to be published: KAO, EON, BAG

\section{Conflict of Interest}

There is no conflict of interest.

\section{Acknowledgements}

This research was supported with funds from the Government of Ghana University Lecturers' Research Allowance. Assistance with haematological analysis was provided by the technical and laboratory staff of the Department of Molecular Medicine Sciences of the Kwame Nkrumah University of Science and Technology, Kumasi.

\section{References}

AOAC (Association of Official Analytical Chemists) (2005). Official Methods of Analysis of the Official Association of Analytical Chemists (18th ed.). Arlington, VA: Association of the Official Analytical Chemists

Badiola, M., Basurko, O.C., Piedrahita, R., Hundley, R., \& Mendiola, D. (2018). Energy use in Recirculating Aquaculture Systems (RAS): A review. Aquacultural Engineering, 81, 57- 70.

Badiola, M., Mendiolam D., \& Bostock, J. (2012). Recirculating aquaculture systems (RAS) analysis: main issues on management and future challenges. Aquacultural Engineering, 51, 26-35.

Bligh, E.G., \& Dyer, W.J. (1959). A rapid method for total lipid extraction and purification. Canadian Journal of Biochemistry and Physiology, 37, 911-917

Bregnballe, J. (2015). A Guide to Recirculation Aquaculture: An introduction to the new environmentally friendly and highly productive closed fish farming systems. Publication of Food and Agriculture Organization of the United Nations (FAO) and EUROFISH International Organisation

Dalsgaard, J., \& Pedersen, P.B. (2011). Solid and suspended/dissolved waste $(\mathrm{N}, \mathrm{P}, \mathrm{O})$ from rainbow trout (Onchorhynchus mykiss). Aquaculture, 313, 92-99

Davidson, J., Good, C., Welsh, C., Brazil, B., \& Summerfelt, S. (2008). Water quality and treatment efficiency in replicated recirculating systems for salmonids operated under (1) high feed and low flushing conditions or (2) low flushing with or without ozonation. Aquaculture Engineering Society Proceedings VI. 2008 AES Issues Forum, July 23-24, 2008, Roanoke, Virginia, pp. 140158.

Davidson, W. (1997). The effects of exercise training on teleost fish, a review of recent literature. Comparative Biochemistry and Physiology, 117 (1), 67-75.

Davidson, J., Good, C., Welsh, C., \& Summerfelt, S.T. (2011). Abnormal swimming behavior and increased deformities in rainbow trout Oncorhynchus mykiss cultured in low exchange water recirculating aquaculture systems. Aquacultural Engineering, 45, 109-117.

FAO, (2018) State of World Fisheries and Aquaculture 2018 Meeting the sustainable development goals. Rome

Fazio, F., Filicioto, F., Marafioto, S., Di Stefano, V., Assenza, A., Placenti, F., Buscaino, G., Piccione, G., \& Mazzola, S. (2012). Automatic analysis to assess haematological parameters in farmed gilthead sea bream (Sparus aurata Linnaeus, 1758). Marine Freshwater Behaviour and Physiology, 45, 63-73

Fernandes, M.N., \& Rantin, T.R. (1994) Relationship between oxygen availability and metabolic cost of breathing in Nile tilapia (Oreochromis niloticus): aquacultural consequence. Aquaculture, 127, 339-346

Glencross, B.D. (2009). Reduced water oxygen levels affect maximal feed intake, but not protein or energy utilization efficiency of rainbow trout (Oncorhynchus mykiss). Aquaculture Nutrition, 15, 1-8

Good, C., Davidson, J., Welsh, C., Brazil, B., Snekvik, K., \& Summerfelt, S. (2009), The impact of water exchange rate on the health and performance of rainbow trout Oncorhynchus mykiss in water recirculation aquaculture systems. Aquaculture, 294, 80-85

Gorle, J.M.R., Terjesen, B.F., Mota, V.C., \& Summerfelt, S.T. (2018). Water velocity in commercial RAS culture tanks for Atlantic salmon smolt production. Aquacultural Engineering, 81, 89- 100.

Hanan, T.C. (2013). Differences between plasma and serum samples for the evaluation of bloodchemistry values in rainbow trout, channel catfish, hybrid tilapias, and hybrid stripedbass. Journal of Aquatic Animal Health, 11, 116-122

Heinen, J.M., Hankins, J.A., \& Adler, P.R. (1996). Water quality and waste production in recirculating trout culture system with feeding of a higher energy or a lower energy diet. Aquaculture, 27, 699-710

Jobling, M. (1994) Fish bioenergetics. London: Chapman and Hall.

Kramer, D. L. (1987). Dissolved oxygen and fish behavior. Environmental Biology of Fishes, 98, 81-92.

Li, T.C., \& Boyd, C.E. (2016) Comparison of Nessler, phenate, salicylate and ion selective electrode procedures for determination of total ammonia nitrogen in aquaculture. Aquaculture, 450, 187-193

Luo, G., Gao, Q., Wang, C., Liu, W., Sun, D., Li, L., \& Tan, H. (2014), Growth, digestive activity, welfare, and partial cost-effectiveness of genetically improved farmed tilapia (Oreochromis niloticus) cultured in a recirculating aquaculture system and an indoor biofloc system. Aquaculture, 422, 1-7.

Magnoni, L.J., Eding, E., Leguen, I., Prunet, P., Geurden, I., Ozório, R.O.A., \& Schrama, J. W. (2018). Hypoxia, but not an electrolyte imbalanced diet, reduces feed intake, growth and oxygen consumption in rainbow trout (Oncorhynchus mykiss). Scientific Reports, 8, 4965 
Martins, C.I.M., Ochola, D, Ende, S.S.W., Eding, E.H., \& Verreth J.A.J. (2009). Is growth retardation present in Nile tilapia Oreochromis niloticus cultured in low water exchange recirculating aquaculture systems? Aquaculture, 298, 43-50

Martins, C.I., Ochola, D., Ende, S.S., Eding, E.H., \& Verreth, J.A (2009). Is growth retardation present in Nile tilapia Oreochromis niloticus cultured in low water exchange recirculating aquaculture systems? Aquaculture, 298(12), 43-50.

Martins, C.I.M., Eding, E.H., Verdegem, M.C.J., Heinsbroek, L.T.N., Schneider, O., Blancheton, J.P., Roque d'Orbcastel, E., \& Verreth, J.A.J. (2010). New developments in recirculating aquaculture systems in Europe: A perspective on environmental sustainability. Aquacultural Engineering, 43 (3), 83-93

Masaló, I., (2008). Hydrodynamic characterisation of aquaculture tanks and design criteria for improving selfcleaning properties. Ph.D. Thesis. Universitat Politècnicade Cataluntya Barcelona tech, Spain.

Moran, D., Tubbs, L., \& Støttrup, J.G. (2012). Chronic $\mathrm{CO}_{2}$ exposure markedly increases the incidence of cataracts in juvenile Atlantic cod Gadus morhua L. Aquaculture, 364-365, 212-216.

Neves, K.J., \& Brown, N.P. (2015). Effects of dissolved carbon dioxide on cataract formation and progression in juvenile Atlantic cod, Gadus Morhua L. Journal of the World Aquaculture Society, 46, 33-44.

Obirikorang, K. A., Amisah, S., Fialor, S. C., \& Skov, P.V. (2015). Digestibility and postprandial ammonia excretion in Nile Tilapia (Oreochromis niloticus) fed diets containing different oilseed by-products. Aquaculture International, 23, 1249-1260

Obirikorang, K.A., Agbo, N.W., Obirikorang, C., Adjei-Boateng, D., Ahiave, S.E., \& Skov, P.V. (2019). Effects of water flow rates on growth and welfare of Nile tilapia (Oreochromis niloticus) reared in a recirculating aquaculture system. Aquaculture International, 27, 449-462

Obirikorang, K.A., Acheampong, J.N., Duodu, C.P., \& Skov, P.V (2020). Growth, metabolism and respiration in Nile tilapia (Oreochromis niloticus) exposed to chronic or periodic hypoxia. Comparative Biochemistry and Physiology Part A: Molecular \& Integrative Physiology, 248, 110768

Perry, S.F., Jonz, M.G., \& Gilmour, K.M. (2009). Oxygen sensing and the hypoxic ventilator response. In: Richards, J.G., Farrell, A.P., Brauner, C.J. (Eds.), Fish Physiology (vol. 27) Hypoxia (pp. 193-253). London: Elsevier

Schram, E., Verdegem, M.C.J., Widjaja, R.T.O.B.H., Kloet, C.J., Foss, A., Schelvis-Smit, R., Roth, B., \& Imsland, A.K. (2009). Impact of increased flow rate on specific growth rate of juvenile turbot (Scophthalmus maximus, Rafinesque 1810). Aquaculture, 292, 46-52

Skov, P.V. (2019). $\mathrm{CO}_{2}$ in aquaculture. In: Grosell, M., Munday, P.L., Farrell, A.P., Brauner, C.J. (Eds.), Fish Physiology (vol. 37), Carbon Dioxide (pp. 287-321). San Diego: Academic Press.

Sri-uam, P., Donnuea, S., Powtongsook, S., \& Pavasant, P. (2016). Integrated Multi-Trophic Recirculating Aquaculture System for Nile Tilapia (Oreochlomis niloticus). Sustainability, 8, 592 doi:10.3390/su8070592

Summerfelt, S. (2004). Solids flushing, mixing, and water velocity profiles within large (10 and $150 \mathrm{~m}^{3}$ ) circular Cornell-type dual-drain tanks. Aquacultural Engineering, 32, 245-271.

Summerfelt, S.T., Sharrer, M.J., Tsukuda, S.M., \& Gearheart, M., (2009). Process requirements for achieving full-flow disinfection of recirculating water using ozonation and UV irradiation. Aquacultural Engineering, 40, 17-27.

Timmons, M.B., Ebeling, F.W., Wheaton, J.M., Summerfelt, S.T., \& Vinci, J.B. (2002). Recirculating Aquaculture Systems (2nd ed.). Ithaca, NY: Cayuga Aqua Ventures Llc

Tran-Duy. A., Schrama, J.W., van Dam, A.A., \& Verreth, J.A.J. (2008). Effects of oxygen concentration and body weight on maximum feed intake, growth and hematological parameters of Nile tilapia, Oreochromis niloticus. Aquaculture, 275, 152-162

Tsadik, G.G., \& Bart, A.N. (2007). Effects of feeding, stocking density and water-flow rate on fecundity, spawning frequency and egg quality of Nile tilapia, Oreochromis niloticus (L.). Aquaculture, 272(1-4), 380-388.

Turnbull, J.F., Bell, A., Adams, C., Bron, J., \& Huntingford, F.A. (2005). Stocking density and welfare of cage farmed Atlantic salmon: application of a multivariate analysis. Aquaculture, 243: 121-132.

Vosyliené, M.Z. (1999). The Effect of heavy metals on haematological indices of fish (Survey). Acta Zoologica Lituanica, 9:76-82.

Weber, R.E., \& Jensen, F.B. (1988). Functional adaptations in hemoglobins from ectothermic vertebrates. Annual Review of Physiology, 50, 161-179.

Xiao, R., Wei, Y., An, D., Li, D., Ta, X., Wu, Y., \& Ren, Q. (2019). A review on the research status and development trend of equipment in water treatment processes of recirculating aquaculture systems. Reviews in Aquaculture, 11(3), 863-895.

Yogev, U., Vogler, M., Nir, O., Londong, J., \& Gross, A. (2020). Phosphorous recovery from a novel recirculating aquaculture system followed by its sustainable reuse as a fertilizer. Science of The Total Environment, 137949.

Zar, J.H. (1999). Biostatistical Analysis, (4 ${ }^{\text {th }}$ ed.). Englewood Cliff, NJ: Prentice Hall 